Bangladesh J. Bot. 48(4): 1075-1081, 2019 (December)

\title{
ANTIBACTERIAL AND ANTIOXIDANT ACTIVITIES OF AGARICUS BISPORUS (J.E. LANGE) IMBACH FROM PAKISTAN
}

\author{
Hafiz Muhammad Waqas, Muhammad Akbar* and Muhammad SajJad Iqbal \\ Department of Botany, University of Gujrat, Gujrat-50700, Pakistan
}

Keywords: Bioactive constituents, Mushroom, Bactericide, DPPH, GCMS

\begin{abstract}
In the present study, antibacterial and antioxidant (DPPH free radical scavenging activity) activity of an edible mushroom, Agaricus bisporus collected from Pakistan was investigated. In antibacterial assays, $n$ hexane showed 4.83, 3.33, 16 and $3.33 \mathrm{~mm}$ inhibition zone diameter (IZD), chloroform showed 6.33, 16.17, 17 and $1.67 \mathrm{~mm}$ (IZD) while, ethyl acetate exhibited 30, 20, 19 and $28.67 \mathrm{~mm}$ (IZD) against four test plant pathogenic bacteria viz., Pseudomonas syringae Van Hall, Ralstonia solanacearum Yabuuchi et al. Xanthomonas axonopodis Dowson and Erwinia carotovora (Jones) Waldee, at $100 \mathrm{mg} / \mathrm{ml}$ concentration. Optical density (OD) was recorded at $517 \mathrm{~nm}$. n-hexane extract showed 60.73, 47.6 and 33.05\%, chloroform showed 89.97, 82.91 and 77.68\% whereas, ethyl acetate exhibited 89.83, 65.82 and $23.59 \%$ free radical effects as compared to control. Gas chromatography mass spectrometry (GCMS) analysis showed the highest concentration of mono(2-ethylhexyl) phthalate.
\end{abstract}

\section{Introduction}

Natural compounds from mushrooms have been the most important source of biologically active compounds (Mishra and Tiwari et al. 2011, Dimitrijević et al. 2017). These compounds are used in different forms and many of these are still unidentified (Matijaševic et al. 2016). In agriculture, bacterial invasions bring about serious reduction in the quality and yield of crops and incur enormous economic losses (Navarro et al. 2018). At present the most reliable method to control these bacterial pathogens is the use of chemical/synthetic bactericides (Waithaka et al. 2017). But the repeated use of these synthetic compounds causes number of ill effects e.g., health hazards, environmental pollution and antibacterial resistance (Ali and Nejad 2016, Marie et al. 2016, Erjavec et al. 2016). So, there is urgent need to seek nature friendly alternatives to these synthetic chemicals and mushrooms are good source of these alternatives (Gargano et al. 2017). As an example, antibacterial activity of A. bisporus was checked by using acetone, ethanol and water extract against Escherichia coli and Staphylococcus aureus. Acetone, ethanol and water extracts caused 33.9, 61.9 and 78.6\% inhibition in case of E. coli, while there was 35.4, 56.6 and $65.4 \%$ reduction in case of $S$. aureus (Ndungutse et al. 2015). Methanol extracts of wild edible mushrooms, namely Agaricus arvensis, Agaricus campestris, Armillaria mellea, Fomes fomentarius, Coprinus micaceus, Coriolus versicolor and Lactarius deliciosus possess antibacterial and antioxidant properties (Dundar et al. 2016). Extracts of three mushrooms, Terfezia boudieri, Agaricus brunnescens and Lactarius vellereus were tested for their antibacterial potency against bacteria. The chloroform extract of $T$. boudieri exhibited the strongest minimum inhibitory concentration (MIC $2.4 \mu \mathrm{g} / \mathrm{ml}$ ) value against the test microorganism, Streptococcus pyogenes. Maximum antimicrobial effects were observed with the acetone extracts of $T$. boudieri and L. vellereus (MIC $4.8 \mu \mathrm{g} / \mathrm{ml}$ ) against Bacillus subtilis (Doğan et al. 2013).

Antioxidants are the compounds that protect the cell from destruction caused by free radicals through redox reaction carried out by peroxide or oxygen (Hossain et al. 2015). Free radicals destroy the proteins, DNA and sugars present in the plants and antioxidants are the chemicals that

\footnotetext{
*Author for correspondence: <makbarpu@gmail.com>.
} 
delay or stop the formation of these radicals by scavenging effect (Hussein et al. 2015). Various bioactive substances extracted from edible mushrooms have been used against chronic diseases such as cancer, to reduce the oxidative stress and for enhancing the immune function (Jayasuriya et al. 2015, Gargano et al. 2017). Mushrooms have phenolic compounds and vitamins which are known to be excellent antioxidants (Muruke 2014). Important iron chelators that act as free radical's scavengers are found in some mushrooms (Pal et al. 2010).

Agaricus bisporus (Button mushroom) is a Basidiomycete fungus, native to Europe and America. Many studies show that this mushroom has antibacterial (Dániel et al. 2016) and antioxidant activity (Xu et al. 2016). As there are numerous investigations regarding isolation of bioactive compounds having antibacterial and antioxidant activity of A. bisporus throughout the world but such reports are missing on Pakistani mushroom species. Moreover, previous studies regarding antibacterial and antioxidant activity of A. bisporus were mostly conducted on human/animal related pathogens and very few on plant pathogens. So, in the present investigation, antibacterial activity was determined on some notorious plant pathogenic bacteria viz. Pseudomonas syringae, Ralstonia solanacearum, Xanthomonas axonopodis and Erwinia carotovora. These bacteria cause a number of serious plant diseases e.g., canker, necrotic spots, bacterial wilt, rot diseases and lesions in number of crop plants e.g., tomato, pepper, egg plant and citrus. These bacteria have been difficult to control by synthetic pesticides (Doolotkeldieva et al. 2016). So, the present study was undertaken to evaluate bioactivities of constituents of A. bisporus partitioned through organic solvents like $n$-hexane, chloroform and ethyl acetate. This study would help to recognize natural eco-friendly bioactive constituents in A. bisporus.

\section{Materials and Methods}

Isolates of bacterial species with accession number viz. Pseudomonas syringae (FCBP-PB0405), Ralstonia solanacearum (FCBP-PB-0407), Xanthomonas axonopodis (FCBP-PB-0001) and Erwinia carotovora (FCBP-PB-0421) were purchased from culture bank of University of the Punjab, Lahore, Pakistan. These bacterial cultures were subcultured on Lysogeny broth (LB) medium for mass culturing and stored in a refrigerator at $4{ }^{\circ} \mathrm{C}$ for further use.

A. bisporus mushroom, (white, cultivated), was purchased from Margalla Mushroom Industries, Islamabad, Pakistan. The mushroom was sun dried for 7 days. The dried mushroom was ground to powder in pestle and mortar. This dried mushroom powder $(220 \mathrm{~g})$ was first soaked into 1.5 litre methanol $(\mathrm{BDH})$ in a glass jar for 7 days and after that the mixture was filtered by using Whatman no.1 filter paper and evaporated by using rotary evaporator (Model: Heidolph Laborata 4000 efficient) at $45^{\circ} \mathrm{C}$. This methanolic extract was further reconstituted with distilled water $\mathrm{dH}_{2} \mathrm{O}$ and then partitioned with different organic solvents viz. $n$-hexane, chloroform and ethyl acetate, in order of their increasing polarity in separating funnels to obtain the $n$-hexane, chloroform and ethyl acetate extracts. Resulting extracts were stored at $4{ }^{\circ} \mathrm{C}$ for further use.

For the determination of antibacterial activity of different solvent extracts, bioassays were performed by using disk diffusion method as described by (Shameem et al. 2017) with some modifications. All bacterial species were grown on Lysogeny broth (LB) medium and then $6 \mathrm{~mm}$ disk of filter paper was cut out with the help of paper punch. After that, this filter paper was soaked into different concentrations of various solvent extracts of $A$. bisporus and placed onto the streaked test bacterial cultures and incubated at $30^{\circ} \mathrm{C}$. All treatments were replicated thrice. Antibacterial activity was measured with the help of scale after $72 \mathrm{hrs}$ in terms of zone of inhibition (IZD).

For the determination of antioxidant activity of test mushroom, A. bisporus, concentrated extracts in $n$-hexane, chloroform and ethyl acetate were used as described by Rashid et al. (2017), 
with little modifications. All partitioned extracts @ 10, 20 and $30 \mu \mathrm{g} / \mathrm{ml}$ were dissolved in 100\% methanol and raised the final volume up to $4.0 \mathrm{ml}$. After that $1 \mathrm{ml}$ of $0.2 \mathrm{mM}$ 2,2-diphenyl-1picrylhydrazyl (DPPH) solution was added into these solutions and shacked the solution vigorously. The solutions were kept at dark for $15 \mathrm{~min}$ and after that absorbance was measured at $517 \mathrm{~nm}$ by using spectrophotometer (Model: UV3000 Spectrophotometer). DPPH radical scavenging activity was calculated by using the formula;

Inhibition $(\%)=[($ Control absorbance $)-($ Sample absorbance $) /($ control absorbance $)] \times 100$

The biochemical constituents of organic solvent extracts viz. $n$-hexane, chloroform and ethyl acetate of A. bisporus showing higher potency were analyzed by using GCMS.

For statistical analysis, ANOVA was performed followed by DMRT to delineate the treatment means.

\section{Results and Discussion}

Agaricus bisporus mushroom samples collected from Pakistan were investigated for its potency regarding antibacterial activity against four notorious plant pathogens as well as its antioxidant 2,2-diphenyl-1-picrylhydrazyl (DPPH) radical scavenging potential. For this purpose, mushroom extracts were prepared in methanol and then partitioned with other organic solvents viz. $n$-hexane, chloroform and ethyl acetate. The potency of these organic solvent extracts was investigated using different concentrations, 50 and $100 \mathrm{mg} / \mathrm{ml}$. DPPH was recorded in terms of optical density (OD) of 10,20 and $30 \mu \mathrm{g} / \mathrm{ml}$ extracts solutions as compared with control. The most active fraction was analysed by GCMS analysis.

Data about the antibacterial effect of $n$-hexane, chloroform and ethyl acetate extracts are shown in Fig. 1 (A, B, C and D). Different concentrations of $n$-hexane, chloroform and ethyl acetate extracts ranging from 50 to $100 \mathrm{mg} / \mathrm{ml}$ showed antibacterial activity and exhibited significant effect over control. Antibacterial activity was evaluated in terms of measuring zone of inhibition caused by known quantity as well as concentration of particular organic solvent extract e.g., $n$-hexane, chloroform and ethyl acetate organic solvent extracts. $n$-hexane extract caused $2.17,1,10.67$ and $1 \mathrm{~mm}$ inhibition zone at $50 \mathrm{mg} / \mathrm{ml}$ concentration while, at $100 \mathrm{mg} / \mathrm{ml}$ concentration it exhibited 4.83, 3.33, 16 and $3.33 \mathrm{~mm}$ inhibition zone diameter (IZD) against four test plant pathogenic bacteria viz. Pseudomonas syringae, Ralstonia solanacearum, Xanthomonas axonopodis and Erwinia carotovora, respectively. At $50 \mathrm{mg} / \mathrm{ml}$ concentration, chloroform extract showed 2.33,11.67, 14 and 1.17 while at $100 \mathrm{mg} / \mathrm{ml}$ it showed $6.33,16.17,17$ and $1.67 \mathrm{~mm}$ (IZD). Ethyl acetate extract exhibited 15, 7.83, 15.17 and 16.17 at $50 \mathrm{mg} / \mathrm{ml}$ and at $100 \mathrm{mg} / \mathrm{ml}$ it revealed pronounced inhibitory effects causing 30, 20, 19 and $28.67 \mathrm{~mm}$ (IZD) against four test plant pathogenic bacteria, P. syringae, $R$. solanacearum, $X$. axonopodis and E. carotovora, respectively. The present results showed resemblances with the reports of earlier workers (Kang et al. 2015, Soltanian et al. 2016, Waithaka et al. 2017) on A. bisporus during their research and exhibited $4 \mathrm{~mm}$ IZD against $R$. solanacearum. Ashok et al. (2013) also reported antibacterial activity that showed conformity with the present results, where petroleum ether, chloroform and methanolic extract of mushroom Hygro cybeparvula showed $4 \mathrm{~mm}$ inhibition zone against $P$. syringae. Recently, Dimitrijević et al. (2017) investigated the antibacterial activity of six mushroom species from Serbia. Out of these six mushrooms only four mushrooms, namely Boletus fechtneri, Boletus rhodoxanthus, Boletus appendiculatus and Xerocomus badius exhibited antibacterial activity against Pseudomonas aeruginosa, a plant and human pathogen. In this case, disc diffusion bioassays were conducted by methanolic extracts of mushrooms but these were able to induce $14,12.14$ and $11 \mathrm{~mm}$ inhibition zone against $E$. coli. The inhibition zone observed 
during the present studies are more pronounced as compared to earlier research work performed by other workers throughout the world. Moreover, A. bisporus extracts partitioned by different organic solvents used in the present study and tested against a number of plant pathogenic bacteria have not been reported earlier. As different solvent extracts used in the present investigation exhibited very pronounced inhibitory effects against a number of plant pathogenic bacteria as compared to previous studies, this difference in more promising results can be attributed to more quantity of antibacterial compounds present in mushroom sample grown and collected from Pakistan as compared to Agaricus mushroom samples used in previous studies in other parts of the world. This argument is further strengthened by the fact that habitat where mushrooms and plants are being grown greatly affects the metabolism of plants/mushrooms thereby developing different metabolites both in terms of quantity and quality (Tsungai et al. 2016). This change in metabolite profile leads to differential bioactivities that can be harnessed on industrial scale for which mushrooms samples having pronounced bioactivities like used in this study are better options in future.
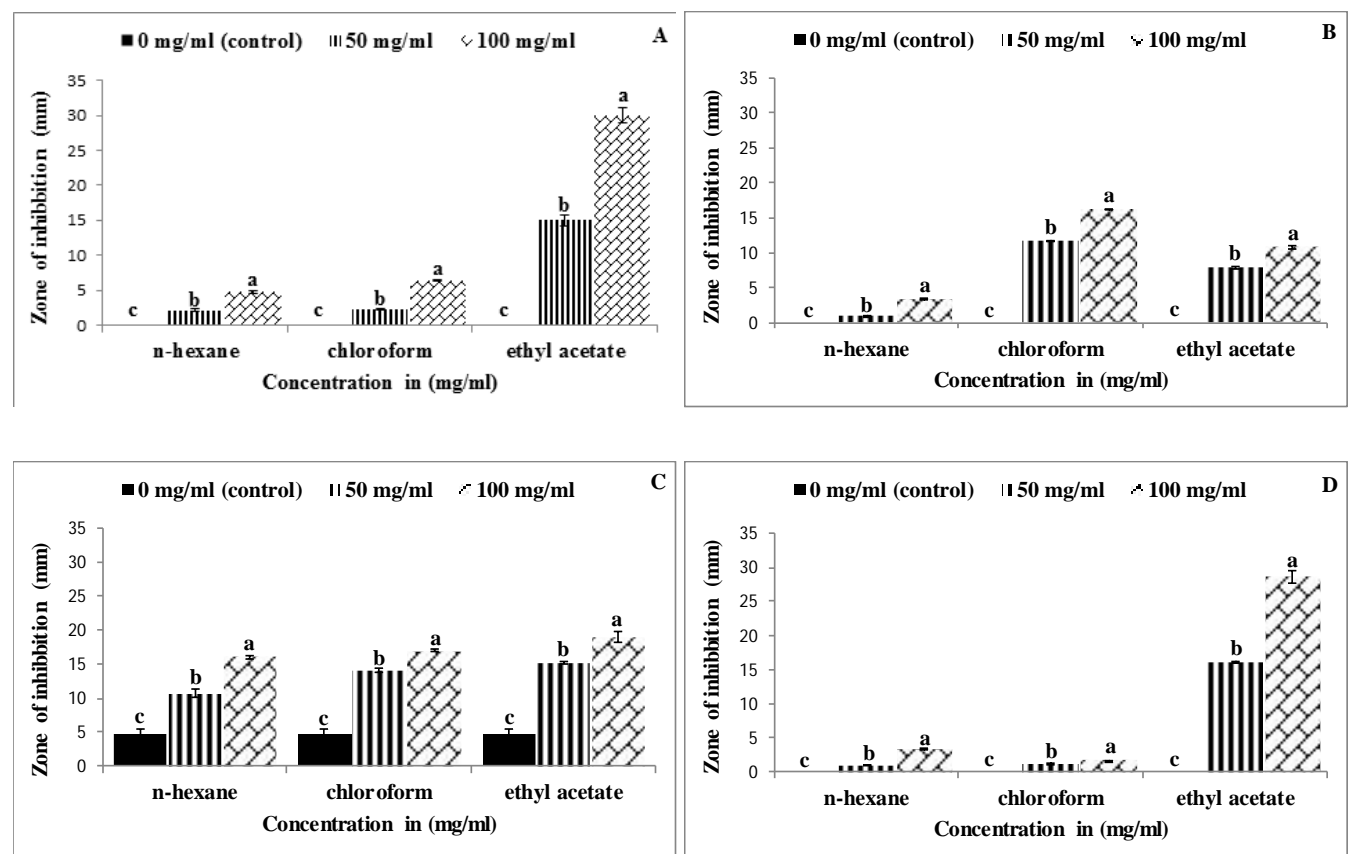

Fig. 1. Effect of different concentrations of $n$-hexane, chloroform and ethyl acetate extract of Agaricus bisporus on growth of (A) Ralstonia solanacearum, (B) Pseudomonas syringae, (C) Erwinia carotovora and (D) Xanthomonas axonopodis.

Values with different letters at their top show a significant difference $(P \leq 0.05)$, as determined by DMRT. Vertical bars show standard errors of means of three replicates.

To record the antioxidant activity of $n$-hexane, chloroform and ethyl acetate extracts of $A$. bisporus, optical density (OD) was taken at $517 \mathrm{~nm}$. $n$-hexane extract showed 60.73, 47.6 and $33.05 \%$, chloroform depicted $89.97,82.91$ and $77.68 \%$ whereas ethyl acetate exhibited 89.83 , 65.82 and $23.59 \%$ free radical effects at 10,20 and $30 \mu \mathrm{g} / \mathrm{ml}$ as compared to control (Fig. 2A and B). In case of antioxidant bioassays, similar results were reported in methanolic and aqueous extract of dry fruiting bodies of A. bisporus collected from Kodaikanal, India that resulted 88.2, 
87.5 and $67.57 \%$ free radical scavenging activity against control DPPH (Razia et al. 2016). In another investigation, A. bisporus (brown, cultivated) water extract showed $88.64 \%$ DPPH radicalscavenging activity (Buruleanu et al. 2017). The presence of antioxidant activity in a number of mushrooms belonging to different species having variable activity have also been reported (Magdziak et al. 2017).
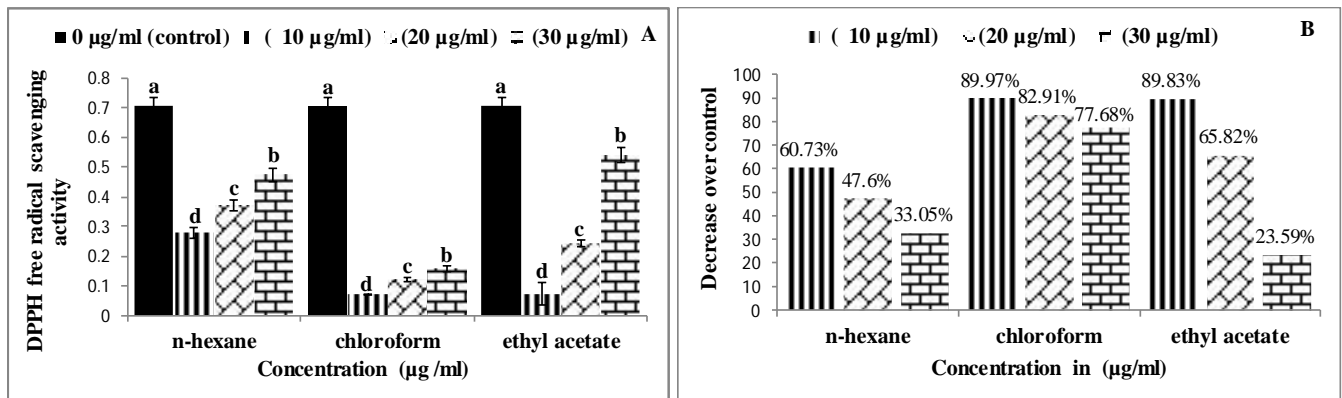

Fig. 2. (A) Antioxidant (DPPH free radical scavenging) activity of n-hexane, chloroform and ethyl acetate extract of Agaricus bisporus, (B) Percentage reduction in DPPH free radical scavenging activity due to different concentrations of n-hexane extract over control.

Values with different letters at their top show a significant difference $(P \leq 0.05)$, as determined by DMRT. Vertical bars show standard errors of means of three replicates.

In the present study, GCMS analysis of ethyl acetate fraction of A. bisporus showed the presence of one compound, mono(2-ethylhexyl) phthalate which showed the highest concentration. Alshammaa (2017) reported similar compound during their research work. Phthalates are naturally occurring bioactive constituents. These have diverse properties from being used as curative drugs, antimicrobial (Ramasany et al. 2010) and anticancer (Rahdary and Sobati 2012), e.g., Diisobutyl phthalate, Dibutyl phthalate and 1,2-benzene-dicarboxylic acid, mono(2ethylhexyl) phthalate. It was concluded that this compound being in highest concentration in the ethyl acetate fraction of A. bisporus mushroom is responsible for different bioactivities like antibacterial and antioxidant activity, recorded in the present study. The present study concludes that A. bisporus collected from Pakistan has better antibacterial and antioxidant potency that can be exploited as nature friendly alternatives to commercial/synthetic compounds.

\section{References}

Ali F and Nejad PA 2016. Antimicrobial, antioxidant and cytotoxic effect of Molybdenum trioxide nanoparticles and application of this for degradation of ketamine under different light illumination. J. Photochem. Photobiol. B: Biol. 159: 211-217.

Alshammaa DAS 2017. Phytochemical investigation and quantitative comparison of ergosterol between Agaricus bisporus and Pleurotus ostreatus by HPLC and GC-MS methods. Int. J. Pharm. Sci. Rev. Res. 44: 215-220.

Ashok C, Naika R, Aruna KB and Jayashree KK 2013. In vitro antibacterial activity of Hygro cybeparvula (Peck) Pegler. Int. J. Pharm. Life Sci. 4: 3080-3086.

Buruleanu LC, Radulescu C, Georgescu AA, Danet FA, Olteanu RL, Nicolescu CM and Dulama ID 2017. Statistical characterization of the phytochemical characteristics of edible mushroom extracts. Anal. Lett.doi.org/10.1080/00032719.2017.1366499.

Dániel K,Vettera J, Ott PG and Móriczb AM 2016. Investigation of antibacterial components of button mushroom (Agaricus bisporus) by direct bioautography and HPLC-DAD-MS. J. Liq. Chromatogr. \& Relat. Technol.39: 298-302. 
Dimitrijević M, Jovanović VS, Cvetković J, Mitić M, Petrović G, Dorđević A and Mitić V 2017. Phenolics, antioxidant potentials, and antimicrobial activities of six wild Boletaceae mushrooms. Anal. Lett. 50: 1691-1709.

Doğan HH, Duman R, Özkalp B and Aydin S 2013. Antimicrobial activities of some mushrooms in Turkey. Pharm. Biol. 51: 707-711.

Doolotkeldieva T, Bobusheva S and Suleymankisi A 2016. Biological control of Erwinia carotovora ssp. carotovora by Streptomyces species. Adv. Microbiol. 6: 104-114.

Dundar A, Okumus V, Ozdemir S, Celik KS, Boğa M and Ozcagli E 2016. Determination of cytotoxic, anticholinesterase, antioxidant and antimicrobial activities of some wild mushroom species. Cogent Food Agric. 2: 1-9.

Erjavec J, Ravnikar M, Brzin J, Grebenc T, Blejec A, Gosak MZ, Saboti`c J, Kos J and Dreo T 2016. Antibacterial activity of wild mushroom extracts on bacterial wilt pathogen Ralstonia solanacearum. Plant Dis. 100: 453-464.

Gargano ML, Van Griensven LJLD, Isikhuemhen O, Lindequist U, Venturella G, Wasser SP and Zervakis GI 2017. Medicinal mushrooms: Valuable biological resources of high exploitation potential. Plant Biosyst. 151: $548-565$.

Hossain SJ, Sultana MS and Iftekharuzzaman M, Hossain SA and Taleb MA 2015. Antioxidant potential of common leafy vegetables in Bangladesh. Bangladesh J. Bot. 44: 51-57.

Hussein JM, Tibuhwa DD, Mshandete AM and Kivaisi AK 2015. Antioxidant properties of seven wild edible mushrooms from Tanzania. Afr. J. Food Sci. 9: 471-479.

Jayasuriya W, Wanigatunge CA, Fernando GH, Abeytunga DTU and Suresh TS 2015. Hypoglycaemic activity of culinary Pleurotus ostreatus and $P$. cystidiosus mushrooms in healthy volunteers and type 2 diabetic patients on diet control and the possible mechanisms of action. Phytother. Res. 29: 303-309.

Kang HW, Kwak AM, Min KJ and Lee SY 2015. Water extract from spent mushroom substrate of Hericium erinaceus suppresses bacterial wilt disease of tomato. Mycobiology 43: 311-318.

Magdziak Z, Siwulski M and Mleczek M 2017. Characteristics of organic acid profiles in 16 species of wild growing edible mushrooms. J. Environ. Sci. Health. Part. B. 52: 784-789.

Marie FO, Brito MR, Cabannes D, Clément A, Spataro C, Moinard M, Dias ES, Callac P and Savoie JM 2016. The genetic linkage map of the medicinal mushroom Agaricus subrufescens reveals highly conserved macrosynteny with the congeneric species Agaricus bisporus. G3: Genes|Genomes Genetics 6: 1217-1226.

Matijaševic D, Pantic M, Raškovic B, Pavlovic V, Duvnjak D, Sknepnek A and Nikšic M 2016. The antibacterial activity of Coriolus versicolor methanol extract and its effect on ultrastructural changes of Staphylococcus aureus and Salmonella enteritidis. Front. Microbiol. 7: 1226-1301.

Mishra BB and Tiwari VK 2011. Natural products: An evolving role in future drug discovery. Eur. J. Med. Chem. 46: 4769-4807.

Muruke MH 2014. Evaluation of antioxidant and iron chelating activities of a wild edible oyster mushroom Pleurotus cystidiosus from Tanzania. Food Sci. Qual. Manag. 2: 9-18.

Navarro MJ, Francisco J, Gea FG and González AJ 2018. Identification, incidence and control of bacterial blotch disease in mushroom crops by management of environmental conditions. Sci Hort. 229: 10-18.

Ndungutse V, Mereddy R and Sultanbawa Y 2015. Bioactive properties of mushroom (Agaricus bisporus) stipe extracts. J. Food Process. Pres. 1: 1-9.

Pal J, Ganguly S, Tahsin KS and Acharya K 2010. In vitro free radical scavenging of wild edible mushroom, Pleurotus squarrusulus (Mont.) Singer. Indian J. Exp. Biol. 47: 1210-1218.

Rahdary AA and Sobati Z. 2012. Chemical composition of essential oil, antibacterial activity and brine shrimp lethality of ethanol extracts from Sedum pallidum. J. Med. Pl. Res. 6: 3105-3109.

Ramasany H, Man Ck, Ju SK, Chellam B, Sundaram J and Moon SH 2010. Identification and antimicrobial activity of combined extract from Azadirachta indica and Ocimum Sanctum. Israeli J. Aquacul.-Baidgeh 62: 85-95. 
Rashid MA, Ashraf A, Nazir S, Nadeem R, Iqbal J, Jabbar S, Ahmed A and Tareen RB 2017. Chemical composition and biological (antioxidant, antimicrobial and haemolyitc) activities of essential oils of an endemic plant (Thymus linearis subsp. Hedgei jalas). Rom. Biotechnol. Lett. 22: 12560-12567.

Razia M, Kumar VS, Sathishkumar G, Sivaramakrishnan S and Sujatha K 2016. Evaluation of phytoconstituents, in vitro antioxidant and antimicrobial activities of edible white button mushroom Agaricus bisporus. Int. J. Pharm. Pharm. Sci. 8: 7-71.

Shameem N, Kamili AN, Ahmad M, Masoodi FA and Parray JA 2017. Antimicrobial activity of crude fractions and morel compounds from wild edible mushrooms of North Western Himalaya. Microb. Pathog. 105: 356-360.

Soltanian H, Rezaeian SH, Shakeri A, Janpoor J and Pourianfar HR 2016. Antibacterial activity of crude extracts and fractions from Iranian wild-grown and cultivated Agaricus spp. Biomed. Res. 27: 56-59.

Tsungai R, Kashangura C, Chidewe C, Benhura MA and Mduluza T 2016. Antibacterial properties of wild edible and non-edible mushrooms found in Zimbabwe. Afr. J. Microbiol. Res. 10: 977-984.

Waithaka PN, Gathuru EM, Githaiga BM and Onkoba KM 2017. Antimicrobial activity of mushroom (Agaricus bisporus) and fungal (Trametes gibbosa) extracts from mushrooms and fungi of Egerton main campus, Njoro Kenya. J. Biomed. Sci. 6:3-10.

Xu Y, Tian Y, Ma R, Liu Q and Zhang J 2016. Effect of plasma activated water on the post harvest quality of button mushrooms. Agaricus bisporus. Food Chem. 197: 436-444.

((Manuscript received on 5 February, 2018; revised on 26 July, 2018) 